\title{
BMJ Open Prevalence of simultaneous use of alcohol and prescription medication in older adults: findings from a cross- sectional survey (Health Survey for England 2013)
}

John Foster, Swatee Patel

To cite: Foster J, Patel S. Prevalence of simultaneous use of alcohol and prescription medication in older adults: findings from a cross-sectional survey (Health Survey for England 2013). BMJ Open 2019;9:e023730. doi:10.1136/ bmjopen-2018-023730

- Prepublication history for this paper is available online. To view these files, please visit the journal online (http://dx.doi org/10.1136/bmjopen-2018023730).

Received 26 April 2018 Revised 30 April 2019 Accepted 30 May 2019

\section{Check for updates}

(c) Author(s) (or their employer(s)) 2019. Re-use permitted under CC BY-NC. No commercial re-use. See rights and permissions. Published by BMJ.

Psychology, Social Work and Counselling, University of Greenwich, London, UK

Correspondence to Dr John Foster;

j.h.foster@gre.ac.uk

\section{ABSTRACT}

Objectives To investigate the concurrent use of 'atrisk' (AR) drinking (>10 units of alcohol per week) and prescription medications, while controlling for sociodemographic, and health-related factors, among older adults (aged 65-89 years).

Design Cross-sectional survey.

Setting Data from Health Survey of England, 2013. Interventions None.

Participants General population survey of 2169 adults aged 65-89 years.

Primary outcome measures AR drinking ( $>10$ units per week). Secondary outcome was AR drinking defined as $>14$ units of alcohol per week limit (the cut-off used by the Department of Health for AT drinking).

Results Twenty-seven per cent $(n=568)$ of the sample were AR drinkers. Factors associated with alcohol consumption were gender, age, social class, marital status, rurality of dwelling, deprivation index, self-reported genera health, cigarette smoking, body mass index, exercise level, health and well-being scores' and number of prescription drugs. Logistic regression analysis showed that males were more likely to be AR drinkers $(\mathrm{OR} 3.44,95 \% \mathrm{Cl} 2.59$ to $4.57, p<0.0001$ ) than females. Each year increase in age, lowered the probability of AR drinking by a factor of 0.95 (95\% Cl 0.93 to $0.98, \mathrm{p}<0.0001)$. Using prescription drugs reduced AR drinking by a factor of $0.92(95 \% \mathrm{Cl}$ 0.85 to $0.93, p=0.033$ ), after controlling for age, sex and rurality of dwelling. No other predictors were significant. Similar results were obtained for AR drinking of $>14$ units per week.

Conclusion AR drinking is more likely in older men than women. The odds of AR drinking lessens, as individuals age, and using prescription drugs also reduces $A R$ drinking.

\section{INTRODUCTION}

In the UK, it is estimated that around 17\% of the population are now over the age of 65 years. ${ }^{1}$ The general trend is for alcohol consumption to decline with age. ${ }^{2}$. However, a recent paper $^{3}$ has stated that individuals within the age band 55-74 years (now often
Strengths and limitations of this study

The research uses data from a gold-standard general population health survey.

- To our knowledge, this is the first study that has shown there is a negative relationship between being prescribed medication and at-risk drinking in older adults (aged 65-89 years).

- Health Survey of England (HSE) relies on self-report when assessing alcohol consumption.

- There is a high probability of under-reporting of alcohol consumption in the HSE.

referred to as baby boomers), is the only one where the percentage of individuals drinking above the daily limits have increased during the last 5 years. The sensible drinking limits in the UK have recently been reduced to 14 units per week for both men and women with a further recommendation of two alcohol-free days. ${ }^{4}$ Prior to this, it was 14 units per week for women and 21 units for men. ${ }^{5}$ During the last decade, there has been a $20 \%$ increase in the number of people over 65 years drinking above the daily limits at least 1 day per week. ${ }^{6}$ The Royal College of Psychiatrists $(\mathrm{RCP})^{7}$ recommended guidelines in the UK should be lowered to 1.5 units of alcohol per day (10.5 units per week), with at least two alcohol-free days per week, for individuals over 65 years. A second edition of the report $^{8}$ suggested that the revised national guidelines ${ }^{4}$ may still be too high for older people with physical or mental health problems who are taking medications.

According to the 2015 Health Survey of England (HSE), around half of the people over the age of 65 years in the England regularly take prescription medication. ${ }^{9}$ As the body ages, it becomes more susceptible to alcohol-drug interactions, and metabolises 
both alcohol and drugs less efficiently. Even a small amount of alcohol (2-3 units), when taken in combination with some prescription drugs, can cause adverse effects. ${ }^{10}$ A systematic review has shown that prescription medication including psychotropic drugs are frequently used in combination with alcohol. ${ }^{11}$ A US study found that the prescription of cardiovascular, central nervous system (CNS) and metabolic agents was commonplace in current drinkers over 65 years of age, ${ }^{12}$ and similar work from Ireland found that heavy drinking was associated with the prescription of anticoagulants/antiplatelets, cardiovascular and CNS agents. ${ }^{13}$ Non-steroidal anti-inflammatory drugs, which are commonly used by older adults, can cause stomach bleeding, gastric inflammation and kidney damage if taken in combination with alcohol. ${ }^{14}$ Alcohol can also enhance the sedative effects of some medications, such as muscle relaxants and benzodiazepines, which can lead to falls and even death. ${ }^{15}$ Despite the increased likelihood of being prescribed multiple drugs the $\mathrm{RCP}^{78}$ state that older people are often given confusing and conflicting advice on how much they can drink or no advice at all.

To date, there have been no studies in the UK which have looked at 'at-risk' (AR) drinking using the limits recommended by the $\mathrm{RCP}^{7}$ and compared them to the new Department of Health guidelines. ${ }^{4}$ This study uses data collected from the $\mathrm{HSE}^{16}$ which is regarded as a gold-standard general population survey and data are quoted from it in National Health Service Statistics. ${ }^{17}$

The aim of the study is to examine the concurrent use of AR drinking ( $>10$ units of alcohol per week) and prescription medications, while controlling for sociodemographic, and health-related factors, among older adults (aged $65-89$ years).

\section{METHODS}

\section{The Health Survey of England}

The study uses data collected from the HSE which has been conducted annually since 1991 on adults aged 16 years or more. The data used in the current study is from HSE 2013. The core modules that are repeated regularly are demographic characteristics, general health, longstanding illness, doctor-diagnosed hypertension, diabetes, smoking and alcohol consumption. Prescription medication was especially collected for the HSE 2013 and is not routinely collected.

\section{Assessment of AR drinking}

The current study uses the cut-off points for AR drinking as those who drink $>10$ units of alcohol per week. The 10.5 (not including two alcohol-free days) unit limit is regarded as the cut-off for AR drinking in older adults in accordance with the recommendations of the RCP. ${ }^{7}$ The nearest category to the RCP cut-off point used by the HSE is 10 units per week, which is used in the current study. The 14 units of alcohol per week, limit is the current
Department of Health AR drinking guidelines ${ }^{4}$ which is a cut-off also used by the HSE.

\section{Data collection}

The HSE sample was selected using a stratified random probability sample of private households in England. In 2013, 8795 adults aged 16 years and over and 2185 children ages 2-15 years were interviewed at households from the selected addresses and 6183 adults and 1455 children had a nurse visit when measurements such as blood samples were taken and data were recorded concerning prescription drug use. Thus, our sample (aged 65-89 years) consisted of $2169(24.6 \%)$ participants who had the interview, and 1607 (25.9\%) who received the nurse visit. Ethical approval for this wave of the study was provided by the Oxford A Research Ethics Committee (reference number: $12 / \mathrm{SC} / 0317){ }^{18}$

\section{Patient and public involvement}

The data are derived from a secondary dataset and there is no direct patient involvement in this study. Details of arrangements for patient and public involvement can be obtained through University College London. ${ }^{16}$

\section{Socio demographic measures}

In this study, the variables age, gender, education level, employment status, ethnicity, religion, marital status, household type, rurality of dwelling, Index of Multiple Deprivation (IMD) ${ }^{19}$ and social class were used. The IMD was calculated by assigning a number of indices of deprivation/affluence to a specific locality. They are divided into quintiles and higher quintiles equate to greater deprivation. Social class categorisations were assigned with reference to the Office of Population Surveys ${ }^{20}$ and occupations were coded according to Office of National Statistics guidance. ${ }^{21}$

\section{Indicators of physical and mental health}

Measures of height $(\mathrm{cm})$, weight $(\mathrm{kg})$, BMI, blood cholesterol levels and blood pressure were collected. Diet was also assessed regarding the amount of fruit and vegetables consumed. Each adult was asked to rate their current general health on a scale of very good, good, fair, bad and very bad. This was converted into a score of 1-5 (higher scores indicated better health). Level of physical activity was assessed by the International Physical Activity Questionnaire. ${ }^{22}$ Individuals record the amount of time they spent carrying out physical activities such as walking. The Warwick and Edinburgh Mental Well-being Scale $\left(\right.$ WEMWBS ${ }^{23}$ was used which assesses mental health wellbeing across the general population and its validity and reliability is well established where higher scores indicate better mental health status. ${ }^{24}$

\section{Cigarette and alcohol consumption}

Participants were asked how many cigarettes they typically smoked daily and to compile a drinking diary concerning the amount of alcohol consumed in the last 7 days. This was then subsequently converted into units of alcohol 
consumed per week. In the UK, a unit of alcohol is $8 \mathrm{~g}$ of pure alcohol, the equivalent of half a pint of normal strength beer. ${ }^{25}$

\section{Prescription medications}

Participants were asked whether they had been prescribed any of the following medications in the last 7 days; antidepressants, analgesia, antihypertensives, cardiovascular, antidiabetic medications, proton-pump inhibitors, antiplatelet, lipid-lowering, antiasthma/Chronic Obstructive Pulmonary Disease (COPD) and antibacterial medications. The use of over the counter (OTC), medication purchased at a pharmacy, was not recorded in the survey.

\section{Statistical analysis}

SPSS V.23 was used for all statistical analyses. A two-sided $p$ value of $<0.05$ was considered statistically significant.

In stage 1 analysis (of all participants), $\chi^{2}$ test, one-way Analysis of Variance (ANOVA) and Kruskal-Wallis test were used.

In stage 2 analysis, only the individuals who consumed any alcohol in the last 7 days were included. Logistic regression model was used, with the dependent variable as $A R$ versus not-AR drinkers. A cut-off using 10 units of alcohol per week as cut-off was used as the primary outcome measure for AR drinking, and a secondary outcome measure used a cut-off was 14 units of alcohol per week. All variables which were significant in the bivariate analysis in stage 1 , were used as predictors in the logistic regression model of stage 2 . The variable, total number of prescription drugs taken, included the 10 drugs: analgesics, antibacterial, antidepressants, antidiabetic, antihypertensives, antiplatelet, asthma/COPD, cardiovascular, lipid-lowering and proton-pump inhibitor. A further analysis using only nine of these drugs (removing antidepressants) was carried out, as it was the only psychotropic medication compared with the others. A comparison was also made, to assess the representativeness, of the subset of individuals who provided prescription drug use data, with all participants in the full sample.

\section{RESULTS}

Sociodemographic, cigarette and alcohol consumption data for the study sample are shown in table 1 . There were 2169 (52.2\% women) participants in the sample aged $65-89$ years. Mean age in the sample was 73.7 years (SD $6.5)$. There was no difference in the mean age between men and women $(\mathrm{p}=0.402)$. Over $92 \%$ of individuals was White British and the majority were married (59.8\%), affluent (IMD quintiles 1 and 2: 47.5\%) and lived in urban areas $(75.2 \%)$. Most had retired $(87.7 \%)$, but the most common social class categories (based on employment when working) were II and IIIN.

Over $90 \%$ of individuals were non-smokers. Nearly $40 \%(\mathrm{n}=822)$ were either non-drinkers or typically drank $<1$ unit per week. In total, 26.8\% $(\mathrm{n}=568)$ individuals were drinking $>10$ units of alcohol per week and 20.5\%
Table 1 Percentage of sociodemographic, smoking and drinking categories in the sample

\begin{tabular}{|c|c|c|}
\hline Variable (n) & Category & $\%$ \\
\hline \multirow[t]{2}{*}{ Gender (2169) } & Male & 47.8 \\
\hline & Female & 52.2 \\
\hline \multirow[t]{2}{*}{ Ethnicity (2158) } & White British & 92.2 \\
\hline & Other & 7.8 \\
\hline \multirow[t]{5}{*}{ Marital status (2169) } & Single & 5.6 \\
\hline & Married & 59.8 \\
\hline & Divorced/separated & 10.4 \\
\hline & Widowed & 24 \\
\hline & Other & 0.2 \\
\hline \multirow{3}{*}{$\begin{array}{l}\text { Rurality of dwelling } \\
\text { (2169) }\end{array}$} & Urban & 75.2 \\
\hline & Town and fringe areas & 11.8 \\
\hline & Rural & 13 \\
\hline \multirow{5}{*}{$\begin{array}{l}\text { Deprivation index, IMD } \\
(2169)\end{array}$} & Quintile 1 (least) & 23.7 \\
\hline & Quintile 2 & 23.8 \\
\hline & Quintile 3 & 22.4 \\
\hline & Quintile 4 & 15.8 \\
\hline & Quintile 5 & 14.2 \\
\hline \multirow[t]{6}{*}{ Social class ${ }^{2122}(2087)$} & I professional & 4.9 \\
\hline & II managerial/technical & 28.6 \\
\hline & IIIN skilled non-manual & 24.5 \\
\hline & IIIM skilled manual & 20 \\
\hline & IV semiskilled manual & 16.2 \\
\hline & V unskilled manual & 5.8 \\
\hline \multirow[t]{4}{*}{ Cigarettes per day (2162) } & Non-smoker & 90.6 \\
\hline & Light $(<10)$ & 3.1 \\
\hline & Moderate (10-20) & 4.1 \\
\hline & Heavy $(>20)$ & 2.2 \\
\hline \multirow{10}{*}{$\begin{array}{l}\text { Alcohol consumption, } \\
\text { last } 7 \text { days ( } 2119)\end{array}$} & None (last 12 months) & 21.7 \\
\hline & $<1$ unit & 17 \\
\hline & $1-7$ units & 27.7 \\
\hline & $>7-10$ units & 6.7 \\
\hline & $>10-14$ units & 6.2 \\
\hline & $>14-21$ units & 7.2 \\
\hline & $>21-28$ units & 4.9 \\
\hline & $>28-35$ units & 3.3 \\
\hline & $>35-50$ units & 3 \\
\hline & $>50$ units & 1.9 \\
\hline
\end{tabular}

IMD, Index of Multiple Deprivation.

$(\mathrm{n}=435)$ drinking $>14$ units per week. The most commonly prescribed drug was cardiovascular medications $(n=927)$, followed by lipid-lowering medications $(n=729)$ and antihypertensives $(n=665)$. The total number of drugs taken by individuals, treated as a continuous variable gave a mean of 2.5 drugs per individual $(\mathrm{SD}=1.9$, range $=0-8$, 
$\mathrm{n}=1638$ ), with $79.4 \%$ taking at least one of the prescribed medications.

Sixty-three per cent $(n=1373)$ of participants had their BMI measured, and $26.5 \%$ were normal/underweight (BMI <25), 43.3\% overweight (BMI 25-29), 20.8\% obese 1 (BMI) $30-34$ ) and $9.2 \%$ obese 2 (BMI $>34$ ). Fiftyfive per cent $(\mathrm{n}=1197)$ of participants provided cholesterol data, and of these $49.9 \%$ had total cholesterol levels $>5 \mathrm{mmol} / \mathrm{L}$. Nearly $75 \% \quad(\mathrm{n}=1459)$ of individuals had their blood pressure measured. Taking the cut-off as a systolic reading of 140 or more ${ }^{26} 35.9 \% \quad(n=524)$ could be classified as having hypertension. Only $28.4 \%$ of participants ate five or more portions of fruit and vegetables daily. The results for self-rating of general health was as follows; very good $/ \operatorname{good} 57.2 \% \quad(\mathrm{n}=1242)$, fair $29.9 \%$ $(\mathrm{n}=650)$ and poor $12.9 \%(\mathrm{n}=277)$. Over $80 \% \quad(\mathrm{n}=1740)$ answered the question concerning physical exercise (time spent walking and no of steps, per day) and $51.8 \%$ were classified low ( $<30 \mathrm{~min},<2500$ steps), $23.7 \%$ medium (30-60 min, 2500-5000 steps) and 24.3\% high (>60 min, $>5000$ steps) ${ }^{22}$ The mental health and well-being scores (WEMWBS) ${ }^{23}$ indicated that most participants had good mental health and well-being $(\mathrm{n}=1846$, mean $=52.0$, $\mathrm{SD}=8.5)$.

The Office of Population Censuses Surveys $(1991)^{20}$ categorisations were used to assign social class, and occupations were coded according to guidance provided (Office of National Statistics 2000). ${ }^{21}$

\section{Stage 1 analysis: all participants}

This analysis included all participants aged 65-89 years. The association between alcohol consumption, and sociodemographic, health-related and prescribed drugs variables, was explored (table 2). The sociodemographic variables that were associated with alcohol consumption were gender (males drinking more, $\chi^{2}(4)=156.710, p<0.0001$ ), social class (I and II, drinking more, $\chi^{2}(20)=93.436, p<0.0001$ ), marital status (married drinking more, $\left.\chi^{2}(12)=62.320, p<0.0001\right)$, rurality of dwelling (urbanites drinking less, $\chi^{2}(8)=24.334, p=0.002$ ) and deprivation index IMD (most deprived drinking less, $\left.\chi^{2}(16)=73.994, p<0.0001\right)$.

The health-related factors that were associated with alcohol consumption were smoking (moderate/heavy smokers drinking more, $\left.\chi^{2}(12)=23.037, p=0.027\right)$, self-reported general health (decreased use of alcohol with poorer health, $\left.\chi^{2}(8)=121.740, p<0.0001\right)$, exercise levels (higher levels of exercise with less drinking, $\chi^{2}(8)=65.549$, $\mathrm{p}<0.0001)$ and BMI (decreased use of alcohol associated with higher BMI, $\left.\chi^{2}(12)=22.185, \mathrm{p}=0.035\right)$. Blood Pressure $\left(\chi^{2}(8, \mathrm{n}=1434)=5.848, \mathrm{p}=0.664\right)$ and cholesterol levels $(\mathrm{F}(4,1177)=1.420, \mathrm{p}=0.225)$ were not associated with alcohol consumption.

One thousand six hundred and seven participants $(75.8 \%)$ provided data on prescription drug use in the last 7 days and of these $(n=1301,790.4 \%)$ were taking at least one prescription drug. As only $75.8 \%$ of the participants had provided data on prescription drugs, a check on the representativeness of this subset of individuals, to the full sample, was made in terms of their age, gender, ethnicity, social class and alcohol consumption, which showed no difference in these factors (table 3).

The prescription drugs associated to alcohol consumption in the last 7 days, were antidepressants $\left(\chi^{2}(4)=15.341\right.$, $\mathrm{p}=0.004)$, analgesics $\left(\chi^{2}(4)=27.503, \mathrm{p}<0.0001\right)$, cardiovascular medications $\left(\chi^{2}(4)=19.561, p=0.001\right)$ and antidiabetic drugs $\left(\chi^{2}(4)=10.621, \mathrm{p}=0.031\right)$, proton-pump inhibitors $\left(\chi^{2}(4)=17.993, \mathrm{p}=0.001\right)$ and antiplatelets $\left(\chi^{2}(4)=10.798, \mathrm{p}=0.029\right)$ (table 2). Higher prescription drug use was associated with less alcohol consumption or abstinence. Antihypertensive $\left(\chi^{2}(4)=8.758, \mathrm{p}=0.067\right)$, lipid-lowering $\quad\left(\chi^{2}(4)=6.330, \quad \mathrm{p}=0.176\right), \quad$ antiasthma/ COPD $\left(\chi^{2}(4)=7.820, p=0.098\right)$ and antibacterial medication $\left(\chi^{2}(4)=5.213, \mathrm{p}=0.266\right)$ was not associated with alcohol consumption levels. Three continuous variables, also associated with alcohol consumption, were age (OR $-0.279,95 \%$ CI -0.365 to $-0.193, \mathrm{p}<0.001)$, WEMWBS scores (OR $0.101,95 \%$ CI 0.028 to $0.173, \mathrm{p}=0.006$ ) and number of prescription drugs (OR $-0.011,95 \% \mathrm{CI}-0.018$ to $-0.004, \mathrm{p}=0.001$ ).

Variables not statistically significantly associated with alcohol consumption were BP, cholesterol level and prescription medication of antihypertensive, lipid-lowering, antiasthma/COPD and antibacterial medication.

\section{Stage 2 analysis: alcohol drinkers}

All variables which were associated to alcohol consumption in stage 1 analysis, were used as predictors in logistic regressions using AR versus not-AR drinking ( $>10$ units of alcohol in the last 7 days as cut-off). These were gender, age, social class, marital status, rurality of dwelling, deprivation index, general health, cigarette smoking, BMI, exercise level and WEMWBS scores, number of prescription drugs.

Individuals who had not drunk any alcohol in the previous 12 months were excluded. Table 4A shows that men were 3.44 (95\% CI 2.59 to $4.57, \mathrm{p}<0.0001)$ times more likely to be AR drinkers than women, after controlling for age, use of prescription medication and rurality of dwelling. Other variables were not significant predictors. Higher age was associated with a lower probability of AR drinking, by a factor of 0.95 (95\% CI 0.93 to $0.98, \mathrm{p}<0.0001$ ) for each year older the individual is. Using a prescription drug reduces AR drinking by a factor of 0.92 (95\% CI 0.85 to $0.93, \mathrm{p}=0.033$ ). A similar analysis was conducted excluding antidepressants from the total number of drugs taken which showed that there was little difference in the odds ratio (OR $0.92,95 \%$ CI 0.86 to 0.99 , $\mathrm{p}=0.020$ ), compared with the original model in table 4A.

A further logistic regression analysis was conducted using the higher cut-off point for AR drinking of $>14$ units per week (table 4B), which showed similar results to the lower cut-off point logistic regression model. Again, if we excluded antidepressants from the total number of drugs taken, there was little difference in the odds ratio 
Table 2 Sociodemographic, health-related, prescription drug factors with alcohol consumption during last 7 days

\begin{tabular}{|c|c|c|c|c|c|c|}
\hline Variable (n) & $\begin{array}{l}\begin{array}{l}\text { Non- } \\
\text { drinkers }\end{array} \\
\text { n (row \%) }\end{array}$ & $\begin{array}{l}\text { 1-10 units } \\
\mathrm{n} \text { (row \%) }\end{array}$ & $\frac{>10-21 \text { units }}{\mathrm{n} \text { (row \%) }}$ & $\begin{array}{l}>21-35 \text { units } \\
\text { n (row \%) }\end{array}$ & $\begin{array}{l}>36 \text { units } \\
\text { n (row \%) }\end{array}$ & $P$ value \\
\hline Gender (2119) & & & & & & $<0.0001$ \\
\hline Male & $285(28.3)$ & 347 (34.2) & $167(16.5)$ & $128(12.6)$ & $85(8.4)$ & \\
\hline Female & $535(48.4)$ & $382(34.6)$ & $120(10.9)$ & $47(4.3)$ & $21(1.9)$ & \\
\hline Social class (2087) & & & & & & $<0.0001$ \\
\hline I professional & $23(23.0)$ & $43(43.0)$ & $14(14.0)$ & $15(15.0)$ & $5(5)$ & \\
\hline II managerial/technical & $174(29.7)$ & 216 (36.9) & $93(15.9)$ & $62(10.6)$ & $41(7.0)$ & \\
\hline IIIN skilled non-manual & $193(38.6)$ & $190(38.0)$ & $71(14.2)$ & $34(6.8)$ & $12(2.4)$ & \\
\hline IIIM skilled manual & $149(36.8)$ & $127(31.4)$ & $64(15.8)$ & $38(9.4)$ & $27(6.7)$ & \\
\hline IV semiskilled manual & $165(49.1)$ & $114(33.9)$ & $31(9.2)$ & $12(3.6)$ & $14(4.2)$ & \\
\hline V unskilled manual & $65(55.6)$ & $30(25.6)$ & $8(6.8)$ & $11(9.4)$ & $3(2.6)$ & \\
\hline Marital status (2169) & & & & & & $<0.0001$ \\
\hline Single & $49(42.6)$ & $35(30.4)$ & $11(9.6)$ & $14(12.2)$ & $6(5.2)$ & \\
\hline Married & $426(33.5)$ & $456(35.8)$ & $202(15.9)$ & $117(9.2)$ & $72(5.7)$ & \\
\hline Divorced/separated & $87(40.1)$ & $78(35.9)$ & $20(9.2)$ & $17(7.8)$ & $15(6.9)$ & \\
\hline Widowed & $260(50.6)$ & $160(31.1)$ & $54(10.5)$ & $27(8.3)$ & $13(2.5)$ & \\
\hline Rurality of dwelling (2119) & & & & & & 0.002 \\
\hline Urban & $649(40.8)$ & $549(34.5)$ & $204(12.8)$ & $112(7.0)$ & $76(4.8)$ & \\
\hline Town and fringe areas & $84(33.2)$ & $91(36.0)$ & $40(15.8)$ & $27(10.7)$ & $11(4.3)$ & \\
\hline Rural & 89 (32.2) & $89(32.2)$ & $43(15.6)$ & $36(13.0)$ & $19(6.9)$ & \\
\hline Deprivation index, IMD (2119) & & & & & & $<0.0001$ \\
\hline Quintile 1 (least) & $143(28.1)$ & $197(38.8)$ & $90(17.7)$ & $50(9.8)$ & $28(5.5)$ & \\
\hline Quintile 2 & 169 (33.3) & $189(37.3)$ & $70(13.8)$ & $48(9.5)$ & $31(6.1)$ & \\
\hline Quintile 3 & $199(42.0)$ & $165(34.8)$ & $57(12.0)$ & $33(7.0)$ & $20(4.2)$ & \\
\hline Quintile 4 & $149(45.2)$ & $102(30.9)$ & $44(13.3)$ & $22(6.7)$ & $13(3.9)$ & \\
\hline Quintile 5 (most) & $162(54.0)$ & $76(25.3)$ & $26(8.7)$ & $22(7.3)$ & $14(4.7)$ & \\
\hline Cigarettes/day (2117) & & & & & & 0.027 \\
\hline Non-smoker & $732(38.2)$ & $678(35.4)$ & $262(13.7)$ & $152(7.9)$ & $106(5.0)$ & \\
\hline Light $(<10)$ & $35(52.2)$ & $15(22.4)$ & $7(10.4)$ & $5(7.5)$ & $5(7.5)$ & \\
\hline Moderate (10-20) & $30(34.5)$ & $26(29.9)$ & $15(17.2)$ & $11(12.6)$ & $5(5.7)$ & \\
\hline Heavy $(>20)$ & $23(47.9)$ & $10(20.8)$ & $3(6.3)$ & $7(14.6)$ & $5(10.4)$ & \\
\hline General health (2118) & & & & & & $<0.0001$ \\
\hline Very good/good & $366(30.0)$ & $461(37.7)$ & 199 (16.3) & $130(10.6)$ & $66(5.4)$ & \\
\hline Fair & $293(46.7)$ & $201(32.0)$ & $72(11.5)$ & $32(5.1)$ & $30(4.8)$ & \\
\hline Bad/very bad & $163(60.8)$ & $66(24.6)$ & $16(6.0)$ & $13(4.9)$ & $10(3.7)$ & \\
\hline Exercise level (1708) & & & & & & $<0.0001$ \\
\hline Low & $388(43.8)$ & $280(31.6)$ & $95(10.7)$ & $70(7.9)$ & $53(6.0)$ & \\
\hline Medium & $122(29.8)$ & $165(40.3)$ & $63(15.4)$ & $41(10.0)$ & $18(4.4)$ & \\
\hline High & $104(25.2)$ & $162(39.2)$ & $83(20.1)$ & $47(11.4)$ & $17(4.1)$ & \\
\hline BMI (1349) & & & & & & 0.035 \\
\hline Normal/underweight (<25) & $120(33.3)$ & $144(40.0)$ & $50(13.9)$ & $32(8.9)$ & $14(3.9)$ & \\
\hline Overweight $(25$ to $<30)$ & $181(31.2)$ & $229(39.4)$ & $87(15.0)$ & $518.8)$ & $33(5.7)$ & \\
\hline Obese I (30 to <35) & $97(34.4)$ & $104(36.9)$ & $42(14.9)$ & $24(8.5)$ & $15(5.3)$ & \\
\hline Obese II and III ( $(\geq 35)$ & $65(51.6)$ & $34(27.0)$ & $11(8.7)$ & $10(7.9)$ & $6(4.8)$ & \\
\hline
\end{tabular}


Table 2 Continued

\begin{tabular}{|c|c|c|c|c|c|c|}
\hline & $\begin{array}{l}\text { Non- } \\
\text { drinkers }\end{array}$ & $1-10$ units & $>10-21$ units & $>21-35$ units & $>36$ units & \\
\hline \multirow{2}{*}{\multicolumn{7}{|c|}{ Prescription drugs, taken last 7 days (1607) }} \\
\hline & & & & & & \\
\hline Antidepressants, yes & $77(51.3)$ & $43(28.7)$ & $14(9.3)$ & $12(8.0)$ & $4(2.7)$ & 0.004 \\
\hline No & $(35.6)$ & $(37.1)$ & (13.5) & $(8.6)$ & $(5.2)$ & \\
\hline Analgesics, yes & $171(47.5)$ & $118(32.8)$ & $43(11.9)$ & $20(5.6)$ & $8(2.2)$ & $<0.0001$ \\
\hline No & $(34.1)$ & $(37.3)$ & $(13.5)$ & (9.4) & (5.8) & \\
\hline Antihypertensives, yes & $272(55.9)$ & $234(35.2)$ & $80(12.0)$ & $47(7.1)$ & $32(4.8)$ & 0.067 \\
\hline No & $(34.4)$ & $(37.0)$ & (13.9) & $(9.6)$ & $(5.1)$ & \\
\hline Cardiovascular, yes & $381(41.1)$ & $321(34.6)$ & $113(12.2)$ & $64(6.9)$ & $48(5.2)$ & 0.001 \\
\hline No & $(31.6)$ & $(38.5)$ & $(14.4)$ & $(10.7)$ & $(4.7)$ & \\
\hline Antidiabetic, yes & $91(47.2)$ & $64(33.2)$ & $18(9.3)$ & $13(6.7)$ & 7 (3.6) & 0.031 \\
\hline No & $(35.7)$ & $(36.7)$ & (13.6) & $(8.8)$ & (5.2) & \\
\hline Proton-pump inhibitor, yes & $176(46.0)$ & $126(32.9)$ & $39(10.2)$ & $26(6.8)$ & $16(4.2)$ & 0.001 \\
\hline No & $(34.3)$ & $(37.3)$ & $(14.1)$ & $(9.1)$ & $(5.2)$ & \\
\hline Antiplatelet, yes & $168(42.4)$ & $128(32.3)$ & $53(13.4)$ & $24(6.1)$ & $23(5.8)$ & 0.029 \\
\hline No & $(35.3)$ & $(37.6)$ & (13) & $(9.3)$ & $(4.7)$ & \\
\hline Lipid-lowering, yes & $284(39.0)$ & $252(34.6)$ & $89(12.2)$ & $60(8.2)$ & $44(6.0)$ & 0.176 \\
\hline No & $(35.5)$ & $(37.7)$ & $(13.9)$ & (8.8) & $(4.1)$ & \\
\hline Asthma/COPD, yes & $82(42.9)$ & $72(37.7)$ & $16(8.4)$ & $11(5.8)$ & $10(5.2)$ & 0.098 \\
\hline No & $(36.3)$ & $(36.1)$ & $(13.8)$ & $(8.9)$ & $(4.9)$ & \\
\hline Antibacterial, yes & $12(32.4)$ & $19(51.4)$ & $3(8.1)$ & $3(8.1)$ & $0(0.0)$ & 0.266 \\
\hline No & $(37.2)$ & $(35.9)$ & $(13.2)$ & $(8.5)$ & $(5.1)$ & \\
\hline
\end{tabular}

IMD, Index of Multiple Deprivation.

(OR $0.90,95 \%$ CI 0.83 to $0.97, \mathrm{p}=0.005$ ) compared with the model in table $4 \mathrm{~B}$.

\section{DISCUSSION}

\section{Summary}

The main finding from this study shows that there is an association of decreased AR drinking as individuals age, and using prescription drugs is also associated with a reduction in the probability of $\mathrm{AR}$ drinking. A recent $\mathrm{BMJ}_{\text {editorial }}{ }^{3}$ has highlighted that substance misuse (including illicit drugs but predominantly alcohol) by a group they term baby boomers (people born 1946-1964) is likely to treble in the USA and double in Europe by $2020{ }^{27}$ The term baby boomers usually refer to those aged 50 years and above. In the current study, we have only used data collected on individuals 65 years or above and have assessed AR drinking by using criteria suggested for those aged 65 years or above others by the RCP ${ }^{7}$ and the current Department of Health guidelines. ${ }^{4}$

Not-AR drinking was associated with high prescription medication levels, and men were more likely to be AR drinkers than women. There was also an association between rurality of dwelling and AR drinking showing that living in rural areas was associated with a higher level of AR drinking of $>10$ units per week. Greater age, and being on prescribed drugs, was associated with a lower level of AR drinking. This suggests that diminished health status as indicated by being prescribed drugs is associated with less AR drinking in individuals aged 65-89 years. Similar trends were evident when the cut-off point for AR drinking was taken as $>14$ units per week.

\section{Comparison with existing literature}

Our study is consistent with findings that alcohol consumption is likely to reduce because of declining health status ${ }^{28}$ in particular, being on prescription drugs. The finding that community-based men over 65 years are more likely to be AR drinkers than women is similar to data from the American National Survey on Drug Use and Health. ${ }^{29}$ There are indications that living in a rural area or village is associated with a greater likelihood of AR drinking. This is an under-researched area but $\mathrm{Li} e t a l^{30}$ found that Norwegian older adults living in urban areas were more likely to drink alcohol and this was associated with positive health outcomes. In contrast poor health outcomes including greater alcohol consumption were reported in the same paper in a Chinese sample of men 
Table 3 Sociodemographic, and alcohol consumption, comparison of total sample with prescription drug users only

Total sample $(\mathbf{n}=\mathbf{2 1 6 9})$

Prescription drug users only

$\%$ $(n=1301)$

\begin{tabular}{|c|c|c|}
\hline \multicolumn{3}{|l|}{ Gender $(n=2169)$} \\
\hline Male & 47.8 & 48.6 \\
\hline Female & 52.2 & 51.4 \\
\hline \multicolumn{3}{|l|}{ Ethnicity $(n=2158)$} \\
\hline White British & 92.2 & 93.6 \\
\hline Other & 7.8 & 6.4 \\
\hline \multicolumn{3}{|l|}{ Social class $(n=2087)$} \\
\hline I: professional & 4.9 & 4.1 \\
\hline II: managerial/technical & 28.6 & 28.6 \\
\hline IIIN: skilled non-manual & 44.5 & 44.4 \\
\hline IIIM: skilled manual & 20 & 20.1 \\
\hline IV: semiskilled manual & 16.2 & 17.1 \\
\hline V: unskilled manual & 5.8 & 5.9 \\
\hline \multicolumn{3}{|c|}{ Alcohol consumption, last 7 days $(n=2119)$} \\
\hline None in last 12 months, or $<1$ unit & 38.7 & 38.9 \\
\hline $1-10$ units & 34.4 & 34.9 \\
\hline$>10-21$ units & 13.4 & 12.1 \\
\hline$>21-28$ units & 4.9 & 4.6 \\
\hline$>28-50$ units & 6.3 & 5.8 \\
\hline$>50$ units & 1.9 & 1.8 \\
\hline Age, years $(n=2169)$ & Mean=73.7 (SD=6.5) & Mean $=73.9(\mathrm{SD}=6.4)$ \\
\hline
\end{tabular}

living in rural areas. ${ }^{30}$ The association with the diminished likelihood of AR drinking as an individual gets older has been confirmed by international research. ${ }^{31}$ An American survey $(\mathrm{n}=83321)$ of alcohol use and prescription drug in older people ${ }^{32}$ found that nearly twenty percent of the sample reported being prescribed an alcohol interactive medication and continued to drink. This is consistent with our finding that there are a proportion of older people who consume alcohol in combination with those medications known to cause an adverse reaction and are likely to be unaware of the risks involved. ${ }^{7}$ In this context it is noteworthy that one third, of all men and women aged 65 years and over are prescribed four or more types of prescription drug daily ${ }^{33}$ notwithstanding
OTC drug consumption. There was no relationship between social class and AR drinking. The English Longitudinal Study of Ageing (ELSA) ${ }^{34}$ suggests that affluence, higher social class and alcohol consumption is associated with 'successful' ageing. ${ }^{35}$ The $\mathrm{RCP}^{8}$ acknowledged, that alcohol abuse in older people now needs to be considered in the context that alcohol plays in encouraging 'social cohesion'. Important insights are provided by a 10-year longitudinal study ${ }^{36}$ which confirmed that higher social class was associated with greater alcohol consumption, and equally poor self-rated health was associated less alcohol consumption over time. The authors ${ }^{36}$ suggest that as successful ageing could be associated with a level of drinking, as it provides greater opportunities for social

\begin{tabular}{lcc}
\hline Table 4A & Logistic regression model: AR drinkers $(>10$ units per week, $n=566,34.2 \%)$ & versus not-AR drinkers $(n=1093,65.8 \%)$ \\
\hline Variables & OR $(95 \%$ Cl) & P value \\
\hline Gender (reference category: female) & $3.44(2.59$ to 4.57$)$ & $<0.0001$ \\
Age & $0.95(0.93$ to 0.98$)$ & $<0.0001$ \\
Total no of prescription drugs taken & $0.92(0.85$ to 0.93$)$ & 0.033 \\
Rurality of dwelling (reference category: rural) & & 0.046 \\
$\quad$ Urban & $0.74(0.50$ to 1.10$)$ & 0.136 \\
$\quad$ Town and fringe areas & $1.16(0.70$ to 1.92$)$ & 0.568 \\
\hline
\end{tabular}


Table 4B Logistic regression model: AR drinkers ( $>14$ units per week, $n=330,25.6 \%)$ versus not-AR drinkers $(n=960,74.4 \%)$

\begin{tabular}{lll}
\hline Variables & OR $\mathbf{( 9 5 \% ~ C l )}$ & P value \\
\hline Gender (reference category: female) & $3.27(2.49$ to 4.31$)$ & $<0.0001$ \\
Age & $0.97(0.95$ to 0.99$)$ & 0.004 \\
Total no of prescription drugs taken & $0.91(0.84$ to 0.98$)$ & 0.008 \\
Rurality of dwelling (reference category: rural) & & 0.088 \\
$\quad$ Urban & $0.67(0.47$ to 0.96$)$ & 0.028 \\
$\quad$ Town and fringe areas & $0.75(0.47$ to 1.21$)$ & 0.239 \\
\hline
\end{tabular}

interaction, and as health declines there are fewer opportunities to facilitate this. However, it should be noted that ELSA includes individuals who are aged 50 years or more, unlike the current study which only considers those 65 years or more. The finding that being prescribed medication is associated with less AR drinking but not social class suggests that as some individuals age the positive impact of drinking and social class lessens, as their health status diminishes.

\section{Strengths and limitations}

The main strength of this study is that it is based on data taken from an established national dataset using a complex random probability sample derived from post codes. ${ }^{16}$ However, prescription drugs use is reliant on self-report and limited to those included in the survey. Thus, it was not possible to investigate the role of, for example, prescribed psychotropic medication other than antidepressants. The role of OTC medication cannot be assessed as these data were not collected in the HSE. US evidence indicates that older people living in the community, regularly use OTC medication though this was based on self-report data, ${ }^{37}$ and a study across 15 European countries found that in a sample of 46394 adults with chronic pain over half of the sample used OTC analgesic medication. ${ }^{38}$ Alcohol consumption levels reported, may also have been under-estimated. It is likely that heavy drinkers would not participate in a general population survey $^{39}$ this is coupled with a tendency towards underestimation of alcohol consumption in the general population ${ }^{40}$ and into what constitutes a unit of alcohol. ${ }^{41}$ In addition, estimates of reported wine consumption have underestimated the impact of the strength of drinks consumed and the size of glasses in which they are either served or poured. ${ }^{42}$

\section{Implications for research and/or practice}

We suggest that future waves of the HSE continue to survey prescription drug use, but expand the types of prescription drugs being assessed, and consider how to integrate assessing use of OTC medications. Thus, we recommend that public health professionals should highlight the need for GPs, pharmacists and other professionals to address the possible interaction of any prescribed or OTC medications with alcohol in older people. In addition, it would be beneficial to design information leaflets that can be distributed in health centres and pharmacies providing information concerning the interaction between certain prescription drugs/OTC medicines and alcohol. Finally, we also suggest that professional medical training bodies such as the General Medical council (GMC) (medicine), Nursing and Midwifery Council (NMC) (nursing) and General Pharmaceutical Council (GPhC) (pharmacy) address their current curricula to take steps to ascertain current practice and thus ensure that medication interactions with alcohol are addressed.

Contributors Both authors conceived and designed the study. JF obtained the publicly available database and wrote the methodology, results and discussion sections of the paper. SP conducted the statistical analysis for the study and contributed to the writing of the paper. Both authors approved the final manuscript.

Funding The authors have not declared a specific grant for this research from any funding agency in the public, commercial or not-for-profit sectors.

Competing interests None declared.

Patient consent for publication Not required.

Provenance and peer review Not commissioned; externally peer reviewed.

Data sharing statement Extra data are available by emailing the corresponding author, Dr John Foster; j.h.foster@gre.ac.uk.

Open access This is an open access article distributed in accordance with the Creative Commons Attribution Non Commercial (CC BY-NC 4.0) license, which permits others to distribute, remix, adapt, build upon this work non-commercially, and license their derivative works on different terms, provided the original work is properly cited, appropriate credit is given, any changes made indicated, and the use is non-commercial. See: http://creativecommons.org/licenses/by-nc/4.0/.

\section{REFERENCES}

1. Age UK. Later life in the United Kingdom. 2018 http://www.ageuk. org.uk/Documents/EN-GB/Factsheets/Later_Life_UK_factsheet.pdf? dtrk=true.

2. Lader D, Steel M. Opinions survey report no 42 drinking: adults' behaviour and knowledge in 2009: Crown Copyright, 2010.

3. Rao R, Roche A. Substance misuse in older people- Baby boomers are the population at highest risk. BMJ 2017;358.

4. Department of Health. UK chief medical officers low risk drinking guidelines. (August 2016). London: Crown Copyright, 2016.

5. Department of Health. 1995 department of health, sensible drinking - the report of an inter-departmental working group. London: Crown Copyright, 1995.

6. Office of National Statistics. 2017 adult drinking habits. 2017 https://www.ons.gov.uk/peoplepopulationandcommunity/ healthandsocialcare/drugusealcoholandsmoking/datasets/ adultdrinkinghabits (Accessed 21 Mar 2018).

7. Royal College of Psychiatrists. "Our Invisible Addicts". First report of the Older Persons' Substance Misuse Working Group of the Royal College of Psychiatrists. London: Royal College of Psychiatrists, 2011.

8. Royal College of Psychiatrists. Our invisible addicts - 2nd edition. 2018 http://www.rcpsych.ac.uk/files/pdfversion/CR211.pdf (Accessed 21st Mar 2018).

9. NHS Digital. Health survey for England 2015. $2016 \mathrm{https} / /$ digital.nhs uk/catalogue/PUB22610 (Accessed 21st Mar 2018). 
10. Moore AA, Whiteman EJ, Ward KT. Risks of combined alcohol/ medication use in older adults. Am J Geriatr Pharmacother 2007;5:64-74.

11. Ilomäki J, Paljärvi T, Korhonen $\mathrm{MJ}$, et al. Prevalence of concomitant use of alcohol and sedative-hypnotic drugs in middle and older aged persons: a systematic review. Ann Pharmacother 2013;47:257-68.

12. Breslow RA, Dong C, White A. Prevalence of alcohol-interactive prescription medication use among current drinkers: United States, 1999 to 2010. Alcohol Clin Exp Res 2015;39:371-9.

13. Cousins G, Galvin R, Flood M, et al. Potential for alcohol and drug interactions in older adults: evidence from the Irish longitudinal study on ageing. BMC Geriatr 2014;14:57.

14. Weathermon R, Crabb DW. Alcohol and medication interactions. Alcohol Res Health 1999;23:40-54.

15. Maxwell J. et alEpidemiology and demography of nonmedical prescription drug use. In: Crome I, L-T W, Rao T, Crome P, . eds. Substance Use and Older People. New York: Wiley, 2015:109-22.

16. UCL Health and Social Survey Research Group. Health survey for England: 2017. https://www.ucl.ac.uk/hssrg/studies/hse (Accessed 11th Apr 2018)

17. Health Social Care and Information Centre. Statistics on alcohol England 2017. 2017 http://digital.nhs.uk/catalogue/PUB23940 (Accessed 22nd Mar 2018).

18. Health and Social Care Information Centre. Health Survey for England 2013 Volume 1 Health Social Care and Lifestyles. London: Health and Social Care Information Centre, 2013.

19. Department for Communities and Local Government. Index of multiple deprivation score 2010. $2018 \mathrm{http}: / /$ opendatacommunities org/data/societal-wellbeing/deprivation/imd-score-2010 (Accessed 11 Apr 2018).

20. Office of Population Censuses and Surveys. Standard Occupational Classification, Volume 3. London: HMSO, 1991.

21. Office of National Statistics. Standard occupational classifications 2000. Volume 1- structure and description of unit groups. London: HMSO, 2000.

22. Craig CL, Marshall AL, Sjöström M, et al. International physical activity questionnaire: 12-country reliability and validity. Med Sci Sports Exerc 2003;35:1381-95.

23. Crawford MJ, Robotham D, Thana L, et al. Selecting outcome measures in mental health: the views of service users. J Ment Health 2011;20:336-46.

24. Maheswaran $\mathrm{H}$, Weich S, Powell J, et al. Evaluating the responsiveness of the Warwick Edinburgh Mental Well-Being Scale (WEMWBS): group and individual level analysis. Health Qual Life Outcomes 2012:10:156-63.

25. Drinkaware. Unit and Calorie Calculator. $2016 \mathrm{https} / / \mathrm{www}$. drinkaware.co.uk/understand-your-drinking/unit-calculator (Accessed 11th Apr 2018)

26. British and Irish Society of Hypertension. Hypertension guidelines. 2018 http://www.bhsoc.org/latest-guidelines/sub-page-11/ (accessed 12th Apr 2018).
27. Wu LT, Blazer DG. Substance use disorders and psychiatric comorbidity in mid and later life: a review. Int J Epidemiol 2014;43:304-17.

28. Holdsworth $\mathrm{C}$, Mendonça $\mathrm{M}$, Pikhart $\mathrm{H}$, et al. Is regular drinking in later life an indicator of good health? Evidence from the English Longitudinal Study of Ageing. J Epidemiol Community Health 2016;70:764-70.

29. Blazer DG, Wu LT. The epidemiology of at-risk and binge drinking among middle-aged and elderly community adults: National Survey on Drug Use and Health. Am J Psychiatry 2009;166:1162-9.

30. Li J, Wu B, Selbæk G, et al. Factors associated with consumption of alcohol in older adults - a comparison between two cultures, China and Norway: the CLHLS and the HUNT-study. BMC Geriatr 2017:17:172.

31. The Institute of Alcohol Studies. Older people and alcohol. Updated May 2013. London: Institute of Alcohol Studies, London, 2013.

32. Pringle KE, Ahern FM, Heller DA, et al. Potential for alcohol and prescription drug interactions in older people. J Am Geriatr Soc 2005;53:1930-6.

33. Falaschetti E, Malbut K, Primatesta P. Prescribed medication. In: Prior G, Primatesta P, eds. "Health Survey for England 2000. The General Health of Older People and their use of services.". London, TSO: TSO. (The Stationary Office), 2002.

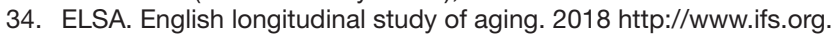
uk/ELSA (Accessed 12th Apr 2018).

35. Iparraguirre J. Socioeconomic determinants of risk of harmful alcohol drinking among people aged 50 or over in England. BMJ Open 2015:5:e007684.

36. Holdsworth C, Frisher M, Mendonça M, et al. Lifecourse transitions, gender and drinking in later life. Ageing Soc 2017:37:462-94.

37. Qato DM, Alexander GC, Conti RM, et al. Use of prescription and over-the-counter medications and dietary supplements among older adults in the United States. JAMA 2008;300:2867-78.

38. Breivik H, Collett B, Ventafridda V, et al. Survey of chronic pain in Europe: prevalence, impact on daily life, and treatment. Eur J Pain 2006;10:287-334.

39. Karlsson T, Simpura J. Changes in living conditions and their links to alcohol consumption and drinking patterns in 16 European Countries. Nordisk Alkohol 2001;18:82-99.

40. Greenfield TK, Kerr WC. Alcohol measurement methodology in epidemiology: recent advances and opportunities. Addiction 2008:103:1082-99.

41. Lovatt M, Eadie D, Meier PS, et al. Lay epidemiology and the interpretation of low-risk drinking guidelines by adults in the United Kingdom. Addiction 2015;110:1912-9.

42. Britton A, O'Neill D, Bell S. Underestimating the alcohol content of a glass of wine: the implications for estimates of mortality risk. Alcohol Alcohol 2016;51:609-14. 